\title{
The Psychology and Parapsychology of Spiritual Emergency
}

\author{
LANCE Storm \\ MONIKA GORETZKI \\ University of Adelaide, South Australia, Australia \\ lance.storm@adelaide.edu.au
}

Submitted June 28, 2020; Accepted November 15, 2020; Published March 15, 2021

https://doi.org/10.31275/20211889

Creative Commons License C-BY-NC

Abstract-A defining aspect of Spiritual Emergency (SE) is a 'Psychic Opening', which may predict psi performance. This study tested paranormal (psi) performance of individuals who had or were having experiences of Spiritual Emergency (i.e. 'SE-experients'), and compared their performance against controls. The study also assessed psychological aspects of SE to differentiate it from psychosis and other proposed psi-inhibitive symptoms-namely, alogia (i.e. poverty of speech), depression, anxiety, and stress. Two groups of participants were formed: controls (mainly psychology students) and SE-experients. Participants either completed the study on a computer in the laboratory or online. Questionnaires on Spiritual Emergency (which includes a subscale on Psychic Opening), positive symptoms of psychosis, alogia, spiritual identity, paranormal belief, mysticism, depression, anxiety, and stress, were administered to participants, who then completed the Imagery Cultivation (IC) pictureidentification psi task, which uses a shamanic-like journeying protocol (Storm \& Rock, 2009a, 2009b). The differences between controls and SE-experients on the psi measures, Direct Hitting (as a percent hit-rate) and Mean Rank Scores, were not significant, but the Sum-of-Ranks difference was highly significant. Also, SE-experients had a marginally significant Mean Rank Score. Direct Hitting did not correlate significantly with any variable, except Rank Scores, which correlated significantly with Psychic Opening, spiritual identity, and paranormal belief, and marginally significantly with Spiritual Emergency. Direct Hitting, Rank Scores, and SE did not correlate significantly with alogia, depression, anxiety, or stress, but the psychosis measure did correlate significantly with alogia, 
depression, anxiety, stress, and SE. The statistical evidence suggests that some proportion of SE-experients experience Psychic Opening. While SE and psychosis overlap, only SE was predicted by spiritual identity, extrovertive mysticism, and paranormal belief (but not alogia), whereas psychosis was predicted by alogia only.

Keywords: imagery cultivation; psychic ability; psychosis; sheep-goat effect; spiritual emergency

\section{INTRODUCTION}

There is no research on the psi-performance capabilities of individuals undergoing Spiritual Emergency (SE; aka transpersonal crisis). Grof and Grof (1991) defined SE as "critical and experientially difficult stages of a profound psychological transformation that involves one's entire being" (p. 31; our italics). Those who experience SE can find themselves in non-ordinary (altered) states of consciousness that "involve intense emotions, visions, and other sensory changes, and unusual thoughts, as well as physical manifestations" (p. 31). As implied in the definitions, emergence (transformation) due to SE seems largely inevitable, though it is an implied outcome; likewise, emergence can occur without the obvious signs of SE: "sometimes the process of spiritual awakening is so subtle and gradual that it is almost imperceptible" (p. 35). As a group, individuals who undergo SE (i.e. 'SEexperients') may be differentiated from the general population by not only having high rates of (self-reported) Psychic Opening, but they may also perform well on objective psi tests. Decades of research on SE and parapsychology give rise to this assumption. The research described in this paper is a step toward clarifying and understanding the suggested relationship among psi, Psychic Opening, and Spiritual Emergency.

\section{Spiritual Emergency, Psychopathology, and Psi}

Grof and Grof $(1989,1991)$ have found SE to be a multidisciplinary concept that assimilates research findings from fields that include experimental and clinical psychiatry and psychology, humanistic and existential psychotherapies, and consciousness research. During SE there can be a marked presence of allegedly 'psychic' (psi) abilities. Specifically, accurate precognition of future situations, clairvoyant 
perception, and telepathic abilities are said to occur while experiencing Psychic Opening (Grof \& Grof, 2017). The Grofs tell us that most of the psychic abilities that emerge during SE tend to be temporary, but for some individuals the successful resolution of the crisis is associated with the emergence of a new capacity or talent such as an increase in creativity, intuitive ability, or, in rare circumstances, the development of a genuine 'psychic gift'. Negative reactions to these experiences can parallel the "psychopathological crisis atmosphere" and "psychotic break" (e.g., delusions, hallucinations) that Ullman (1977, p. 563) mentions, and it is understandable that a clinician might mistake the crisis experience for psychosis.

Little has changed over the decades-indeed, in their comprehensive review, Harris et al. (2019) noted that the mounting evidence for SE as a construct independent of psychosis has helped justify the diagnostic v-code V62.89 in the Diagnostic and Statistical Manual of Mental Disorders, 5th edition (DSM-5; American Psychiatric Association, 2013), but "clinicians are failing to utilize the code due to a lack of understanding and knowledge" (p. 89). But even a casual inspection can reveal a difference: While the individual afflicted by a true psychosis lacks the insight to see that the condition has something to do with their own psyche, SE-experients are "lucid and have a sense of their own inner processes [and] realize that the changes in their experiential world are due to the changes they are experiencing within and are not the cause of external events" (Grof \& Grof, 1991, p. 44). Also, while SE (insofar as it is a noticeable crisis state) might at first appear like psychosis, and vice versa, psychosis does not promise emergence: a "gradual and subtle unfolding of spirituality that leads to a profound shift in values and/or a more fulfilling way of life" (Cooper et al., 2015, p. 243).

Psychosis and SE do bear some similarities; they even correlate (see Bronn \& Mcllwain, 2015). However, the evidence shows that SE differs from psychosis (Bronn \& Mcllwain, 2015; Harris et al., 2015), and it is noted that conventional understandings about the latter overlook the spiritual experiences that can prevail during and after psychosis (Goretzki et al., 2009; Grof, 1985; Grof \& Grof, 1989, 1991; Harris et al., 2019; Phillips et al., 2009). Bronn and Mcllwain were among the first to take an empirical approach to the dichotomy, and they found 
that SE is a distinct construct "and should be differentiated from psychopathology" (p. 367). While four related symptoms-namely alogia (disfluency of thought and speech), depression, anxiety, and stress-are often comorbid with psychosis (Buckley et al., 2008; Hales et al., 2014), SE differs from psychosis by its "divergent relationship with alogia, depression, anxiety, and stress" (Bronn \& Mcllwain, 2015, p. 363). Storm et al. (2017) have since confirmed that scores on the Spiritual Emergency Scale (SES; a 30-item scale constructed by Goretzki et al., 2013, to measure Spiritual Emergency) do not correlate significantly with depression as measured on Beck's Depression Inventory II (BDI-II; Beck et al., 1996).

Harris et al. (2015) have expressed their reservations about the SES, suggesting that crisis variables should correlate with Spiritual Emergency (it being a crisis). And since they showed that psychosis (but not SES) was predicted by dissociation and emotional instability, they defaulted to the conclusion, shared by Cooper et al. (2015), that "the SES is measuring spiritual emergence and not SE" (p. 277). ${ }^{1}$ Of course, an alternative view suggested by such findings is that SE-experients present with a unique set of crises characterized by and related to their experiences (more on this issue in the Discussion).

While the correlations between the SES and various psychosis indicators are significant (Goretzki et al., 2009, 2013), items on Kundalini awakening, shamanic crisis, and Psychic Opening (among others) were included in the SES based on research by Grof and Grof (1989), and these may help demarcate SE from psychosis. We might even assume such factors (especially psychic opening as the term suggests) would logically be better predictors of psychic ability than clinical measures. However, while Storm and Goretzki (2020) found that SES scores correlated significantly and positively with outcome on a precognition task, Psychic Opening did not significantly predict the same outcome, possibly because the sample comprised mostly university students (not individuals undergoing SE), and variance on Psychic Opening was low. The present study aims to address the sampling problem by targeting SE-experients.

In addition, there are important parapsychological implications in the distinction between psychotics and SE-experients, whereby the former are burdened by the negative (depression, anxiety, and stress) 
and cognitive (alogia) symptoms of psychosis, whereas the latter are not (Bronn \& Mcllwain, 2015). Specifically, these symptoms (especially depression and anxiety) are not likely to be psi-conducive, whereas paranormal belief (PB) is well-established as being psi-conducive; PB measures often correlate positively with psi performance, indicating the so-called 'sheep-goat effect', with 'sheep' tending to perform above chance on psi tests, and 'goats' not (e.g., see Storm \& Tressoldi, 2017). Specifically, scores on one PB measure (namely the Australian Sheep-Goat Scale; Thalbourne, 1995) correlated significantly with SES and Psychic Opening scores, and the correlation between PB scores and psi-task outcomes was marginally significant for a subsample of paranormal believers (i.e. sheep; see Storm \& Goretzki, 2020). We suggest that PB measures may have a discriminative capacity in that they may help distinguish SE from psychosis. To go further, Thalbourne and Storm (2019) stated that " . . . there is no burgeoning need to pathologize paranormal believers, even if measures suggest a tendency for characteristic symptoms" (p. 181).

A mix of findings exist regarding PB and depression-some studies have found a positive relationship (Thalbourne, 2005; Thalbourne \&Delin, 1994; Thalbourne \& French, 1995), whereas others have found no association between the two (Zebb \& Moore, 2003). Also, an association between depression and anxiety has been partially supported in past research (Billows \& Storm, 2015). It is therefore difficult to say whether depression and anxiety predict PB and/or psychic ability, but it is more likely that they are psi-inhibitive. For example, although Irwin and Watt (2007) report suggestive evidence that anxiety is related to PB, anxiety is linked to neurotic behavior (Palmer, 1978, 1982), with some evidence that highly neurotic participants perform poorly on ESP tests. In other words, positive correlates of PB, like anxiety and depression, are not necessarily psi-conducive even though PB is. Likewise, little or nothing is known about the degree to which two other psychosis correlatesnamely, alogia and stress-affect psi performance (Thalbourne \& Storm, 2019). Generally, therefore, it is not known whether correlates (or hypothesized correlates) of PB, such as alogia, depression, anxiety, and stress, predict psi performance. 


\section{The Study Design}

We aim to test two groups (controls and SE-experients drawn from relevant populations) in a precognitive, picture-identification task that is based on the Imagery Cultivation Model (Storm \& Rock, 2009a, $2009 \mathrm{~b})$. After a shamanic-like journeying protocol is administered, participants attempt to identify a future target picture in a random array that includes four decoys, with success in the task indicated by a 'Direct Hit' (where the target photo was ranked \#1 by the participant). A target pool of 300 pictures compiled by May (2007; see also May et al., 2012) is used-these are presented on a computer monitor. We hypothesize that SE-experients are higher in Psychic Opening than controls (non-SE-experients). It is further hypothesized that SEexperients demonstrate superior psi performance compared with controls. We also aim to determine which of the scales and sub-scales listed below (see Measures) correlate with psychic ability.

A second aim of the study was to show that SE is a distinct and measurable construct, distinguishable from psychosis by its divergent relationship with alogia, depression, anxiety, and stress. To do that we planned to test the internal consistency, and convergent and divergent validity, of two related scales, the SES (already mentioned) and the Experiences of Psychotic Symptoms Scale (EPSS; Goretzki et al., 2009) to confirm the hypothesized differences. Multiple Regression Analyses were also to be conducted to test for predictors of psi ability, psychosis, and SE. This research will further our understanding about Spiritual Emergency, psychosis, and psi ability.

\section{METHODS}

\section{Participants}

Initially, first-year psychology students $(n=92)$, who signed up online, were tested, and they received credit for participation as part of their curriculum program (using the Research Participation System). There were a handful of participants who became aware of the project through flyers or online advertisements on various university websites $(n=8)$. They contacted the principal investigator Lance Storm (L.S.) via ballot-box slip or SMS, so that suitable days and times for testing could 
be arranged. The target of 100 participants for the control sample was attained by Friday, May 3, 2019.

SE-experients had to have experienced (or were experiencing) Spiritual Emergency (SE). They were assessed and approved as suitable by the second author and experimenter (M.G.), who is clinically trained. Many participants self-identified as SE-experients, and they were recruited through websites dedicated to various phenomena experienced during SE. ${ }^{2}$ These participants provided brief outlines of their experiences via email and, where necessary, further information was requested (via phone or email) to determine if the experience contained SE-type phenomena. Some participants were referred to the study by those who had already participated, and others were referred through professional networks dedicated to understanding and studying SE experiences. Through the correspondence, we were able to confirm that we did recruit participants of both types: those who were having and those who had had SE.

The target of $100 \mathrm{SE}$-experients was surpassed as online admissions were not regulated for strategic purposes, as now explained. As is the case with online studies, a small number of participants completed the questionnaires within too short a time period (as fast as $21 / 2$ minutes!), so these were deleted (prior testing showed that 10 to 15 minutes is required just to read all the questionnaires, which does not include audio-listening time of $9^{1 / 2}$ minutes, and time to write the mentation). The number was further reduced by deleting unapproved participants. As the study had to be capped at 100 to eliminate optional extension (a questionable research practice), ${ }^{3}$ legitimate 'spill-over' participants are being held over for a follow-up study (assuming the final number reaches a sizeable proportion). The target for the SE-experient sample of 100 participants was attained by June 15, 2020.

The final sample consisted of 200 participants (as planned) with a mean age of 33 years ( $S D=16$ years); 48 males, 152 females. The mean age of the controls was 23 years $(S D=11$ years); 24 males, 76 females (total $n=100)$. The mean age of the SE-experients was 44 years $(S D=$ 15 years); 24 males, 76 females (total $n=100$ ). The age difference was significant, $t(184.98)=11.08, p<.001$ (two-tailed). (Of course, it is to be expected that SE-experients drawn from the wider community will be older than a student sample.) 


\section{Measures}

(1) Spiritual Emergency Scale (SES; Goretzki et al., 2014): The SES consists of 30 items (see Appendix), each using a five-point Likert scale $(1=$ 'Never' to $5=$ 'Very Often') to measure the experience of SE. Summed scores give an SES score, from 30 to 150. The SES has demonstrated good psychometric properties (Goretzki et al., 2009, 2014). On multiple occasions, the SES has been shown to have a single underlying dimension (Storm \& Goretzki, 2016), it has good test-retest reliability (.84), and it has good convergent and concurrent validity. The SES correlates .70 to .73 with the EPSS, indicating that SE overlaps with psychosis (Bronn \& Mcllwain, 2015; Goretzki et al., 2009). Reliability on Cronbach's $\alpha$ ranges between 0.71 and 0.95 (Bronn \& Mcllwain, 2015).

(2) Experiences of Psychotic Symptoms Scale (EPSS; Goretzki et al., 2009): A 15-item scale, with 12 multiple-choice items measuring positive symptoms of psychosis (EPSS-POS), and a 3 -item multiplechoice subscale to assess the negative psychosis symptom 'Alogia' (i.e. constraints in the production and fluency of thought and speech). Example item: "Have you ever experienced a time when your sentences were unclear or didn't make sense?" Scoring for all items is via fivepoint Likert-scale $(1=$ 'Never' to $5=$ 'Very Often'). Cronbach's $\alpha$ for EPSS-POS $=0.87$, and for Alogia $=0.78$ (Bronn \& Mcllwain, 2015).

(3) Spiritual Identification Scale (SIS; Astin et al., 2011): A 13-item scale to assess the degree to which participants identify themselves as "spiritual" (full-scale theoretical range: 13 to 41). Sample item: "People can reach a higher spiritual plane of consciousness through meditation or prayer." Cronbach's $\alpha=0.88$ (Bronn \& Mcllwain, 2015).

(4) Rasch-Scaled Australian Sheep-Goat Scale (RASGS; Thalbourne, 1995): An 18-item scale measuring belief and alleged experience of paranormal phenomena. Each item scores: o points (False), or 1 point (Uncertain), or 2 points (True). Raw range is o to 36; Raw Mean $=18$. The ASGS data are then top-down purified (Rasch-scaled) to eliminate age and gender bias from the scale (Lange \& Thalbourne, 2002), and this procedure alters the scoring range and mean (standardized mean $=25$, $S D=5$ ). RASGS scores range from 8.13 to 43.39 . Cronbach's $\alpha$ ranges between 0.91 and 0.95 (Billows \& Storm, 2015; Storm \& Thalbourne, 2005). 
(5) Mysticism Scale (MS; Hood, 1975): A 32-item multiple-choice scale that assesses commonly reported mystical experiences that provide the "basic essence to human religious experience" (Hood, 1975, p. 29). The MS comprises three factors (Hood, et al., 1993): Introvertive Mysticism (e.g., an "experience of nothingness"; Hood et al., 2001, p. 692), Extrovertive Mysticism (e.g., "the self reaches a unity with the multiplicity of objects in the universe"; Hood et al., 2001, p. 692), and Religious Interpretation ("experience expressed in explicit religious language"; Hood \& Francis, 2013, p. 36). Items are scored on fivepoint scales ranging from definitely not true $(-2)$ to definitely true $(+2)$. Cronbach's $\alpha$ for the subscales range between 0.77 and 0.92 (Bronn \& Mcllwain, 2015).

(6) Depression Anxiety Stress Scales (DASS-21; Lovibond \& Lovibond, 1995): A 21-item multiple-choice scale that measures three state factors (Depression, Anxiety, Stress) with seven items allocated to each. Participants rate their depression, anxiety, and stress on a four-point Likert-type scale ranging from o ('Did not apply to me at all; i.e. NEVER') to 3 ('Applied to me very much, or most of the time; i.e. ALMOST ALWAYS'). Scores range theoretically from o to 21. Cronbach's $\alpha$ ranges between 0.76 and 0.91 (Bronn \& Mcllwain, 2015).

\section{Materials}

Materials include a computer program containing Information and Consent pages (i.e. screens), plus separate pages for each of the measures listed above. Also presented are a page of five photographs with rank-scoring boxes for each photo, an outcome page, and a feedback page.

\section{Apparatus}

(1) A gallery of 300 photographs compiled by May (2007) from the Corel Stock Photo Library of Professional Photographs. The picture set consists of 12 Groups $\times 5$ Categories $\times 5$ Photographs $=300$ photographs (presented onscreen via desktop computer or laptop).

(2) A true-noise Random Number Generator (Schmidt 1970, 1973). The RNG was purpose-built by Helmut Schmidt (dimensions: $25 \times 30 \times$ $7.5 \mathrm{~cm}$ ). On the face side are 12 green lamps in a circular array and a red LED score-display in the center. 
(3) Imagery Cultivation Audio (.mp3) sound file (13 MB; duration: $9^{1 / 2}$ minutes) containing instructions in the form of guided imagery in conjunction with relaxing meditative music (administered through headphones; for details, see Step 2 in Procedure below).

\section{Procedure}

The following two types of participants were tested:

Controls. Control participants (mainly first-year psychology students) signed up on the School of Psychology website (Research Participation System) for testing in the experimenters' laboratory (one session to complete the measures and the psi test). Other students sought participation after seeing online advertisements or flyers advertised around the campus.

SE-Experients. Participants first had to meet the criteria for suitability, and this was done by email or telephone interview conducted by the second experimenter (M.G.). Suitable participants were given a unique identifying code to log in to the test website where they completed the measures and the psi test (data were time-stamped to confirm validated participation).

Step 1. Instructions outlining the experiment were presented onscreen, and if participants chose to participate, they moved to another page that listed a series of consent statements. Participants then provided demographics details, and completed the SES, EPSS, SIS, RASGS, MS, and DASS-21.

Step 2. Via onscreen message, all participants were informed that they would undergo the Imagery Cultivation (IC) procedure (duration: $9^{1 / 2}$ minutes). They were asked to relax in their chair, start the prerecorded instructions, close their eyes, and listen via headphones to pre-recorded instructions (audio) adapted from Harner (1990): Excerpt: ". . . Now visualise the future target photograph before you. Study the photograph in all its detail. Remember this information for later." Participants could not proceed to Step 3 unless they listened to the audio. After the audio, they answered a test question, and were then instructed to type onscreen notes (mentation) about their impressions of the future target. At this stage, neither the participant nor the experimenters (L.S. or M.G.) knew what the target was since it had not yet been generated. 
Step 3. Five photographs were selected using a randomization method in the computer application for SE-experients, or the RNG for controls. The selection procedure followed May et al.'s (2012) recommendation. First, the computer or RNG randomly selected one Group of twelve, followed by one photograph from each of five Categories in that Group, all taken from the fuzzy set, encoded target pool totaling 300 photographs. Target selection did not take place until Step 5.

Step 4. Ranking-Once the set of five photos appeared onscreen, the experimenter instructed the participant to rank the five photographs from 1 to 5 (\#1 = 'most likely' photo that matches the mentation, to \#5 = 'least likely' photo that matches the mentation). The participant was permitted to re-read his/her mentation, in order to prompt his/her memory, thereby assisting him/her in the ranking process. Participants had to type under each photo the respective rank number.

Step 5. The computer generated the target photograph from the five that were presented previoiusly onscreen (MCE $=20 \%)$. The computer automatically presented the target as feedback to the participant and gave the rank number that had been given by the participant for that photo (if the photo was ranked \#1, it was a Direct Hit). The participant was debriefed, and confidential results were emailed to each participant at a later date.

\section{Data Analyses}

Part I of the analytical component of this study involved (i) testing the differences on paranormal performance (Direct Hitting, Rank Scores, and Sum-of-Ranks) between SE-experients and controls; and (ii) determining correlations between psi outcomes (Direct Hitting and Rank Scores) and the ten variables on six measures (SES, EPSS, SIS, RASGS, MS, and DASS-21), in accordance with the hypotheses given below. All statistical analyses were conducted using SPSS (Version 26.0).

Part II of the study included confirmatory and exploratory exercises aimed at assessing the psychometric properties of the SES and the EPSS. In particular, these two scales were tested to confirm convergent and divergent relationships between SE and psychosis. As part of these analyses, a correlation matrix was scrutinized to decide whether to conduct Multiple Regression Analyses (MRA) using suitable demographic details (gender, age, etc.) and scale data (EPSS, SIS, RASGS, SES, MS) as Independent Variables. The Dependent Variables 
(DVs) would be a psi measure (Direct Hitting or Rank Score), the SES, and the EPSS.

\section{Hypotheses}

Hypothesis 1. There is a difference in psi-scoring between SEexperients and controls, with SE-experients scoring (i) higher on Direct Hitting, and (ii) lower on Mean Rank Score.

Hypothesis 2. Direct Hitting correlates positively (Rank Scores correlate negatively) with Spiritual Emergency (SE), Psychic Opening (a subscale of SES), spirituality (SIS), paranormal belief (RASGS), and mysticism (MS)—but neither of the two psi measures (Direct Hitting and Rank Score) correlate with psychosis (EPSS-POS), alogia (an EPSS subscale), depression, anxiety, or stress (DASS-21).

\section{RESULTS}

\section{Preliminary Findings}

Direct Hitting for the whole sample was 50 hits out of 200 , or $25 \%$ (where MCE $=20 \%$ ). The effect is significant, Binomial Exact $z=1.68$, $p=.049$ (one-tailed). The Mean Rank Score for the whole sample was 2.84, where $M C E=3.00(M d n=3.00)$. The effect is significant, $t(199)=$ $-1.67, p=.049$ (one-tailed). Ranks are listed in Table 1 .

TABLE 1

Rank Scores: Full Sample $(\mathrm{N}=\mathbf{2 0 0})$

\begin{tabular}{ccc}
\hline \hline Rank Score & Frequency & $\%$ \\
\hline 1 & 50 & 25.0 \\
2 & 37 & 18.5 \\
3 & 39 & 19.5 \\
4 & 44 & 22.0 \\
5 & 30 & 15.0 \\
Total & 200 & 100.0 \\
\hline
\end{tabular}

The 'Sum-of-Ranks' test using the sum of ordinal weighted ranks formula was also calculated (see Solfvin et al., 1978, pp. 97-99). Solfvin et al. assign a score (or 'weight') to all ranks (e.g., rank \#1 scores 1, etc.), and 
then score counts are totaled. ${ }^{4}$ An ordering of observed distributions is therefore induced. For the sample $(N=200)$, the Sum-of-Ranks statistic is significant, $z=3.98, p=3.40 \times 10^{-5}$ (one-tailed). This result seems generous given the $p$ value is three orders of magnitude larger than the $p$ values for the previous two results (i.e. for Direct Hitting and Mean Rank Score). However, Sum-of-Ranks conveys more information than the conservative Direct-Hit count (less so for Mean Rank Score)-for example, note the significant avoidance effect relevant to rank \#5 (a mere 15\%) in Table 1, and upward shifts toward better scoring ranks, $z=1.68, p=.046$.

Statistics for the six measures (and relevant subscales) are given in Table 2, which also shows ANOVA results assessing the differences between the two groups, controls and SE-experients. All differences were significant except for Alogia, DASS-DEP, and DASS-AX (see the Discussion section below for comments).

TABLE 2

Descriptives: Means \& SDs Full Sample $(N=200)$,

Controls $(n=100) \&$ SE-Experients $(n=100)$

\begin{tabular}{lrcccc}
\hline \hline & & & & & \\
Variable & Full Sample & Controls & SE-Experients & $F(1,198)$ & $p(2 \mathrm{t})$ \\
& $(S D)$ & $(S D)$ & $(S D)$ & & \\
\hline & & & & & \\
1a. SES & $66.01(24.79)$ & $49.90(17.57)$ & $82.12(20.05)$ & 146.10 & $<.001$ \\
1b. Psychic Opening & $14.08(5.29)$ & $10.93(4.29)$ & $17.23(4.22)$ & 109.51 & $<.001$ \\
2a. EPSS-POS & $27.00(11.30)$ & $24.36(8.67)$ & $29.63(9.47)$ & 16.86 & .013 \\
2b. Alogia & $6.61(2.72)$ & $6.64(2.79)$ & $6.58(2.65)$ & -0.02 & .876 \\
3. SIS & $32.41(6.57)$ & $28.37(6.06)$ & $36.44(4.15)$ & 120.69 & $<.001$ \\
4. RASGS & $26.33(7.07)$ & $22.11(5.68)$ & $30.55(5.67)$ & 110.51 & $<.001$ \\
5. MS & $110.19(31.38)$ & $89.40(23.86)$ & $130.97(23.19)$ & 156.10 & $<.001$ \\
6a. DASS-DEP & $5.97(4.49)$ & $6.32(4.83)$ & $5.62(4.12)$ & -1.22 & .272 \\
6b. DASS-AX & $6.04(4.39)$ & $6.43(4.56)$ & $5.64(4.19)$ & -1.63 & .203 \\
6c. DASS-ST & $8.07(4.55)$ & $8.71(4.49)$ & $7.42(4.55)$ & -4.08 & .045 \\
\hline
\end{tabular}

SES = Spiritual Emergency Scale; EPSS-POS = Experiences of Psychotic Symptoms Scale (positive symptoms); SIS = Spiritual Identification Scale; RASGS = Rasch-Scaled Australian Sheep-Goat Scale; MS = Mysticism Scale; DASS = Depression Anxiety Stress Scale (DEP = Depression, $\mathrm{AX}=$ Anxiety, $\mathrm{ST}=$ Stress). 


\section{Planned Analyses-Part I}

Hypothesis 1. There is a difference in psi-scoring between SEexperients and controls, with SE-experients scoring (i) higher on Direct Hitting, and (ii) lower on Mean Rank Score:

(i) Direct Hitting for SE-experients was $26 \%$ (26/100), which is higher than the hit rate of $24 \%$ for the controls (24/100). These hit rates are in the directions expected. The Binomial hit-rate for SE-experients could be considered marginally significant (Exact $z=1.38, p=.087$; Effect Size $[E S]=z / V n=.14)$, but controls did not produce a significant hit rate (Exact $z=0.88, p=.189$; $E S=$ .09). A Mann-Whitney test indicated that the difference was not significant, $U=4900.00, p=.435$ (one-tailed); Cohen's $d=.04$.

(ii) The Mean Rank Score for SE-experients was 2.71 (where MCE = 3.00), which is better than the Mean Rank Score for the controls of 2.96. Ranks for both groups are listed in Table 3. A Mann-Whitney test indicated that the difference was not significant, $U=4501.50$, $p=.108$ (one-tailed); Cohen's $d=.17$.

TABLE 3

Rank Scores: Controls and SE-Experients

\begin{tabular}{ccc}
\hline \hline Rank Score & Control Group & $\%$ \\
\hline 1 & Frequency & 24.0 \\
2 & 24 & 17.0 \\
3 & 17 & 16.0 \\
4 & 16 & 25.0 \\
5 & 25 & 18.0 \\
Total & 18 & 100.0 \\
& 100 & \\
Rank Score & SE-Experients Group & $\%$ \\
1 & Frequency & 26.0 \\
2 & 26 & 20.0 \\
3 & 20 & 23.0 \\
4 & 23 & 19.0 \\
5 & 19 & 12.0 \\
Total & 12 & 100.0 \\
\hline
\end{tabular}


For SE-experients, the Sum-of-Ranks statistic was $z=4.94(p<$ $.001 ; E S=.49)$, but for controls the statistic was only $z=0.61(p=.271$; $E S=.06)$. Scoring for SE-experients was significant, and the $z$-score difference $([4.94-0.61] / \sqrt{ } 2=3.06)$ between the two groups was also significant $(p<.01)$. Note, too, for SE-experients, the very low number of hits on rank \#5 of only $12 \%(\mathrm{MCE}=20 \%)$, thus indicating psiavoidance of a non-target $(z=1.87, p=.030)$, suggesting a preference for better ranks.

Hypothesis 2. Direct Hitting correlates positively (Rank Scores correlate negatively) with SES, Psychic Opening, SIS, RASGS, and MSbut neither of the two psi measures correlate with EPSS-POS, alogia, depression, anxiety, or stress.

As some scales were significantly skewed, and Direct Hitting is a dichotomous measure, and Rank-score is ordinal, Spearman's rho tests were conducted. Direct Hitting did not correlate significantly with any of the five variables, although all were positively correlated. However, as predicted, the other five variables (i.e., EPSS-POS, alogia, depression, anxiety, and stress) did not correlate significantly with Direct Hitting, although the correlations were negative.

Rank Scores correlated negatively and significantly with RASGS, $r_{s}(198)=-0.12, p=.048$, so that high paranormal belief scores tended to indicate better Rank Scores. Rank Scores also correlated negatively and significantly with Psychic Opening, $r_{s}(198)=-0.12, p=.049$; and SIS, $r_{s}(198)=-0.13, p=.036$; and marginally significantly with SES, $r_{s}(198)$ $=-0.11, p=.061$. Given these results, we ran a multiple regression analysis (MRA), with Rank Scores as the criterion variable, but the MRA failed. Rank Scores did not correlate significantly with MS (but the correlation was negative). As expected, Rank Scores did not correlate significantly with EPSS-POS (psychosis), alogia, depression, anxiety, or stress (though the correlations were all positive).

\section{Planned Analyses-Part II}

Reliability assessments (internal consistency) for the two scales (SES and EPSS) are indicated using Cronbach's $\alpha$. For the SES, Cronbach's $\alpha=.96$. For the EPSS, Cronbach's $\alpha=.92$. For the measure of positive psychosis symptoms (EPSS-POS), Cronbach's $\alpha=.90$. For alogia, Cronbach's $\alpha=.78$. Bronn and Mcllwain (2015) conducted a 
number of statistical analyses on the SES and EPSS-POS, to evaluate their relationships with each other and with a range of possible correlates; namely, alogia, depression, anxiety, stress, spiritual identity, and mysticism.

For the present study, an inspection of three correlation matrices (one each for full sample, controls, and SE-experients), featuring all relevant psychological variables for confirmatory purposes (10 in total), revealed that all 36 correlations of interest were significant. However, due to multiple testing, the critical alpha $(\alpha=.05)$ was divided by 36 (the number of tests), rendering a new critical $\alpha=1.39 \times 10^{-3}$. The correction left us with 35 (97\%) significant correlations. Table 4 lists the relevant correlations, most of which confirm the theoretical suppositions and/ or past findings (all tests are two-tailed).

TABLE 4

Correlations: Pearson's $r$ for the Full Sample $(N=200)$,

Controls $(n=100)$, SE-Experients $(n=100)$

\begin{tabular}{|c|c|c|c|}
\hline Variable & $r$ (Full Sample) & $r$ (Controls) & $\begin{array}{c}r(S E- \\
\text { Experients) }\end{array}$ \\
\hline 1. EPSS-POS $\times$ Alogia & $.72^{*}$ & $.78^{*}$ & $.73^{*}$ \\
\hline 2. EPSS-POS $\times$ Depression & $.40^{*}$ & $.36^{*}$ & $.54^{*}$ \\
\hline 3. EPSS-POS $\times$ Anxiety & $.41^{*}$ & $.36^{*}$ & $.55^{*}$ \\
\hline 4. EPSS-POS $\times$ Stress & $.37^{*}$ & .33 & $.51^{*}$ \\
\hline 5. Alogia $\times$ Depression & $.51^{*}$ & $.42^{*}$ & $.62^{*}$ \\
\hline 6. Alogia $\times$ Anxiety & $.51^{*}$ & $.43^{*}$ & $.60^{*}$ \\
\hline 7. Alogia $\times$ Stress & $.47^{*}$ & $.36^{*}$ & $.59^{*}$ \\
\hline 8. SES $\times$ EPSS-POS & $.68^{*}$ & $.80^{*}$ & $.60^{*}$ \\
\hline 9. SES $\times$ SIS & $.67^{*}$ & $.46^{\star}$ & $.47^{*}$ \\
\hline 10a. SES $\times$ MS-INT & $.67^{*}$ & $.61^{*}$ & $.40^{*}$ \\
\hline 1ob. SES $\times$ MS-EXT & $.73^{*}$ & $.54^{*}$ & $.54^{*}$ \\
\hline 10c. SES $\times$ MS-REL & $.70^{\star}$ & $.46^{*}$ & $.50^{*}$ \\
\hline
\end{tabular}

Degrees of freedom $(d f)=198$; EPSS-POS $=$ Experiences of Psychotic Symptoms Scale (positive symptoms); SES = Spiritual Emergency Scale; SIS = Spiritual Identification Scale; MS-INT = Introvertive Mysticism; MS-EXT = Extrovertive Mysticism; MS-REL = Religious Interpretation; After correction: ${ }^{\star} p<1.39 \times 10^{-3}$. 
Rows 1 to 7 in Table 4 generally replicate the findings in Bronn and Mcllwain (2015, pp. 362-363) under their Hypothesis 5 for their 'student' sample and their 'spiritual' sample. In our sample, specifically, positive symptoms of psychosis (EPSS-POS) and alogia are positively correlated (full sample, SE-experients, and controls). Other Alogia correlates are listed in Table 4. Also, EPSS-POS is positively correlated with depression, anxiety, and stress for the full sample and the SE-experients (for controls, EPSS-POS is positively correlated with depression and anxiety).

Rows 8 through 10 in Table 4 replicate the findings in Bronn and Mcllwain (2015, p. 363) under their Hypothesis 6 for their 'student' and 'spiritual' samples. In our sample specifically, SE positively correlates with EPSS-POS, spiritual identity (SIS), and the three mysticism factors for the full sample and the two subsamples.

Under their Hypothesis 7, Bronn and Mcllwain (2015) ran regression analyses, and after controlling for a number of variables, they found that depression, anxiety, and stress did not predict SE for their 'student' and 'spiritual' samples. Bronn and Mcllwain also found that alogia predicted SE in their 'spiritual' sample only (not their 'student' sample), whereas alogia predicted positive symptoms of psychosis in both samples. It is to be noted that 'comparisons' of two samples, requiring two separate statistical analyses (one for each sample), is only one approach to evaluating two different datasets. Statistical comparison of two groups (i.e. subsamples) can be achieved in a single hierarchical regression analysis by simply combining the samples into one dataset, and then entering the sample variable in the second of two blocks to determine the unique contribution to the model of the grouping (sampling) variable. We therefore present the results of two hierarchical MRAs; one with SES scores as the criterion variable (i.e. DV), and the other with EPSS-POS scores as the criterion variable.

\section{Hierarchical Multiple Regression Analysis-Spiritual Emergency Scale (SES)}

The significant relationships in our correlation matrix showed a number of intercorrelations justifying an MRA on SES as our criterion variable, which could build a model showing the influence of all relevant variables and also show, hierarchically, any additional 
contribution based on known differences between the samples, as al ready indicated from the statistical differences listed in Table 2. This procedure also gives us an empirical advantage over the zero-order correlations presented in our matrix, in that the MRA Outputs in SPSS report semi-partial correlations (whereby shared variance between the predictor of interest and other predictors is removed while all variance in the criterion variable is left intact). In Block 1 , we entered age, gender, EPSS-POS, Alogia, SIS, MS (i.e. the three subscales, MS-INT, MS-EXT, \& MS-REL), RASGS, depression, anxiety, and stress, and in Block 2 we entered 'sample' (comprising two datasets, controls, and SE-experients, where controls are numerically coded as ' 1 ', and SE-experients are coded as ' 2 ').

The assumptions of normality and linearity, as determined by visual inspection of the histogram, PP-plot, and scatterplot, were not violated. Outliers were determined from the Mahalanobis Distance by which significant outliers are indicated when maximum observed values exceed the critical value given by the chi-square distribution, with degrees of freedom equal to the number of predictors in the model (i.e. 12). The critical $p$ value $(\alpha)$ for this test was set at .001. After the removal of two outliers, the maximum observed distance of 29.80 did not exceed the critical chisquare value of 32.91 . There was faint visual evidence of heteroscedasticity in the scatterplot, and the LOESS line was perhaps not ideal. 5 Specifically, the LOESS line had a slight U-shaped curved, suggesting a questionable structure in the model. This trend might indicate the possibility that the model is not necessarily best described as linear. Multicollinearity was not indicated, as Tolerance was greater than .2 (.37).

Age, gender, alogia, MS-INT, MS-REL, depression, anxiety, and stress were all excluded from Model 1 , but EPSS-POS, SIS, RASGS, and MS-EXT were all positive predictors of SE as given by the significant $t$ values (see Table 5). This model was significant, $F(12,185)=60.75, p<$ .001 (two-tailed). The strongest semi-partial $r$ is EPSS-POS (.29).

In Model 2, 'sample' (i.e. group membership) was a significant positive predictor $(\beta=.20)$, corresponding to an adjusted $R^{2}$ of .812, up from $.798(R=.893)$, yielding a final $R^{2}=.812(R=.901)$, so that the model explains about $81 \%$ of the variance in SES scores (though the adjusted value is slightly lower at $80 \%), F$-change $(1,184)=14.55$, $p<.001$ (two-tailed). The strongest semi-partial $r$ is EPSS-POS (.26), 
TABLE 5

Hierarchical MRA: Predictors of SES Score

\begin{tabular}{|c|c|c|c|c|c|c|c|}
\hline Block & $\Delta R^{2}$ & B & $\begin{array}{l}\text { Std. } \\
\text { Error }\end{array}$ & $\beta$ & $t$ & $p$ & $\begin{array}{c}\text { Semi- } \\
\text { partial } \\
r\end{array}$ \\
\hline Step 1 & .798 & & & & & & \\
\hline EPSS-POS & & 1.27 & .15 & .49 & 8.64 & $<.001$ & .29 \\
\hline SIS & & .63 & .20 & .17 & 3.17 & .002 & .11 \\
\hline RASGS & & .42 & .19 & .12 & 2.19 & .030 & .07 \\
\hline MS-EXT & & .41 & .13 & .22 & 3.20 & .002 & .11 \\
\hline Step 2 & .015 & & & & & & \\
\hline EPSS-POS & & 1.17 & .15 & .44 & 8.03 & $<.001$ & .26 \\
\hline SIS & & .52 & .19 & .14 & 2.69 & .008 & .09 \\
\hline RASGS & & .40 & .18 & .11 & 2.17 & .031 & .07 \\
\hline MS-EXT & & .34 & .12 & .19 & 2.76 & .006 & .09 \\
\hline Sample & & 9.83 & 2.58 & .20 & 3.81 & $<.001$ & .12 \\
\hline
\end{tabular}

$\Delta R^{2}=$ change in $R^{2}$ (between Block 1 and Block 2); $p$ values are two-tailed; $M S-E X T=$ Extrovertive Mysticism; Sample = controls + SE-experients.

followed by 'sample' (.12). As Table 5 shows, all $\beta$ values are significant, and the model at Step 2 is significant overall, $F(13,184)=61.30, p<$ .001 (two-tailed). Therefore, the variable 'sample' made a significant additional contribution to the model as a predictor of SE.

\section{Hierarchical Multiple Regression Analysis-Experiences of Psychotic Symptoms Scale (EPSS)}

We ran an MRA on EPSS-POS as our criterion variable. In Block 1, we entered age, gender, SES, Alogia, SIS, MS-INT, MS-EXT, MS-REL, RASGS, depression, anxiety, and stress, and in Block 2 we entered 'sample'. The assumptions of normality and linearity were not violated. After the removal of the same two outliers in the previous MRA, the maximum observed distance of 29.82 did not exceed the 
critical chi-square value of 32.91. Again, there was faint visual evidence of heteroscedasticity in the scatterplot, though the LOESS line was relatively flat. Multicollinearity was not indicated, as Tolerance was greater than .2(.35).

Virtually all variables were excluded from Model 1, except Alogia and SES, which were positive predictors of EPSS-POS (see Table 6). This model was significant, $F(12,185)=46.82, p<.001$ (two-tailed). The

TABLE 6

Hierarchical MRA: Predictors of EPSS-POS Score

\begin{tabular}{|c|c|c|c|c|c|c|c|}
\hline Block & $\Delta R^{2}$ & B & Std. Error & $\beta$ & $t$ & $p$ & Semi-partial $r$ \\
\hline Step 1 & .752 & & & & & & \\
\hline Alogia & & 1.39 & .18 & .40 & 7.79 & $<.001$ & .29 \\
\hline SES & & .23 & .03 & .59 & 8.64 & $<.001$ & .32 \\
\hline Step 2 & .000 & & & & & & \\
\hline Alogia & & 1.40 & .18 & .40 & 7.76 & $<.001$ & .29 \\
\hline SES & & .22 & .03 & .59 & 8.03 & $<.001$ & .30 \\
\hline Sample & & .37 & 1.17 & .02 & .32 & .751 & .01 \\
\hline
\end{tabular}

$\Delta R^{2}=$ change in $R^{2}$ (between Block 1 and Block 2); $p$ values are two-tailed; $M S-E X T=$ Extrovertive Mysticism; Sample = controls + SE-experients.

strongest of two semi-partial $r$ values is SES (.32), followed by Alogia (.29). In Model 2, 'sample' was not a significant positive predictor (change in $\left.R^{2}=0.00\right)$, indicating no change from $.752(R=.867)$ in Model 1, so that the model explains about $75 \%$ of the variance in EPSS-POS scores (adjusted to 74\%); F-change was not significant. The strongest semi-partial $r$ is SES (.30), followed by Alogia (.29). The $\beta$ values are significant, and the model at Step 2 is still significant overall, $F(13,184)=43.01, p<.001$ (two-tailed). However, 'sample' did not make a significant additional contribution to the model as a predictor of EPSS-POS. 


\section{DISCUSSION}

The results for this study are generally favorable. Outcomes for Hypothesis 1, on group differences between SE-experients and controls, were all in the hypothesized directions for Direct Hitting, Mean Rank Score, and Sum-of-Ranks. While the first two group differences were not significant, the Sum-of-Ranks difference, which is a more sensitive measure, was significant. Also, SE-experients had a marginally significant Mean Rank Score compared with the chance baseline (MCE). Looked at another way, the SE-experients also showed significant avoidance of the poorest rank, \#5. As we hypothesized, the SE-experients also reported more Psychic Opening than controls (see Table 2), which is phenomenologically associated with Spiritual Emergency (SE). It might be argued that Psychic Opening is rarely retained after crisis (see Grof \& Grof, 1991), but we emphasize the point that the second author's (M.G.'s) interviews and correspondence with potential SE-experients were conducted to find participants who had or were having Spiritual Emergency (see Procedure above). Had a majority or all of our SE-experients no longer been experiencing spiritual emergence, the vast majority could be expected to have lost their psi ability (and even be on par with the controls), and we would not have found the differences reported here. It is because we found differences that the SES more likely measures emergency rather than emergence.

Results for Hypothesis 2 were mixed. The hypothesized directions were generally as expected, but none of the Direct-Hitting correlations were significant. The failure of Direct Hitting to correlate significantly with SES, Psychic Opening, spiritual identity (SIS), paranormal belief (RASGS), and mystical experience (MS) is somewhat surprising; it was noted, however, that effects were small $\left(r_{s}<0.1\right)$. However, Rank Score proved to be a better psi measu re-it correlated significantly with RASGS, Psychic Opening, and SIS, and MS was a marginally significant correlate.

We also hypothesized that Direct Hitting would not correlate with the pathological measures, EPSS-POS (positive symptoms of psychosis), alogia, depression, anxiety, and stress-none of these were sig-nificant, but the relationships were negative as we would expect since we regard these pathological conditions as psi-inhibitive (again, effects were small, $r_{s}<.1$ ). As expected, Rank Scores did not correlate 
significantly with EPSS-POS, alogia, depression, anxiety, or stress (though the correlations were all positive).

It is noted in Table 2 that SE (including Psychic Opening), EPSSPOS, SIS, RASGS, and MS, are at significantly higher levels for the SEexperients (compared with controls), but SE-experients are significantly lower in stress (not significantly lower for alogia, depression, and anxiety). It is possible, even likely, that there are psychological advantages in having high levels of spirituality, Psychic Opening, paranormal belief, and mystical disposition, alongside low levels of stress. Indeed, they may act as resilience factors that help combat positive symptoms of psychosis and SE, neither of which can be considered a desired state of mental health, though we do take issue with the claim that the latter indicates psychopathology. As stated by Bronn and Mcllwain (2015) "SEs have the potential to be classified as a spiritual problem under the nonpathological V code of the DSM-V" (p. 348; see also, Lukoff \& Lu, 1998; Turner et al., 1995).

Finally, we ran two MRAs: First, our results support those of Bronn and Mcllwain (2015, p. 363), in that depression, anxiety, and stress did not predict SE. However, we found that alogia did not predict SE, which partly undermines the finding by Bronn and Mcllwain who reported that "alogia significantly predicted SE in the spiritual sample ..., but not in the student sample" (p. 363). Also, EPSS-POS, SIS, extrovertive mysticism (MS-EXT), and RASGS all predicted SE. We note too that the grouping variable 'sample' (which refers to participant source, SE-experients and controls, the latter of which were mainly first-year psychology students) made a statistically significant (albeit minor) additional contribution to the model as a predictor of SE.

In the second MRA, alogia predicted EPSS-POS, but the 'sample' variable did not make an additional contribution above and beyond alogia and SES scores, which confirms the SE overlap mentioned by Bronn and Mcllwain, who note, "SE emerges as a distinct measurable construct, overlapping with positive symptoms of psychosis, distinguishable from the negative dimension of psychosis by its divergent relationship with alogia" (p. 346; see also Harris et al., submitted). Our findings bear this out-alogia does not predict SE, but both alogia and SES scores do predict positive symptoms of psychosis.

A final word on emergency vs. emergence: As noted above, Harris 
et al. (2015) and Cooper et al. (2015) suggested that the SES is a measure of emergence rather than SE. A reviewer of this paper allowed for the possibility that the SES does measure SE, but it mainly picks up emergence. In spite of all the research addressing this dichotomy, we argue that a successful resolution of the issue will depend critically on the appropriateness of the distress/crisis measures chosen as possible predictors of SE. This assumption naturally arises from the fact that the experiences associated with SE (especially if traumatic) constitute, or can lead to, psychological crises unlike other psychosocial stressors or crises. We recommend that research now focus on using the SES that features modified response devices that screen for SE-experients in current emergency and past emergency where only emergence is evident in the latter, and proceed from there to test appropriate crisis variables. As Harris et al. (2019) have advised, these variables would be "spiritual, or transpersonal, in nature," but certainly not be "attributable to a mental disorder" (p. 91; see also Turner et al., 1995). Past research shows deficiencies in this approach and therefore remains largely inconclusive.

In conclusion, the statistical evidence reported in the present paper indicates that SE experients experience more psi and report more Psychic Opening than controls. Rank Score correlated significantly with three measures (Psychic Opening, paranormal belief, and spiritual identity), and correlated marginally significantly with Spiritual Emergency. Direct Hitting, Rank Scores, and SE did not correlate significantly with measures often regarded as comorbid with psychosis (i.e., depression, anxiety, and stress), but the psychosis measure did correlate significantly with alogia, depression, anxiety, stress, and SE. While SE overlaps with psychosis (they predict each other), SE was differentiated from psychosis by not having alogia as a predictor, but does have spiritual identity, paranormal belief, and extrovertive mysticism as predictors (which was not the case for the psychosis measure).

\section{NOTES}

1 For critiques on the SES, see Cooper et al. (2015) and Harris et al. (2015). We have addressed their concerns in Storm and Goretzki (2016).

2 American Center for the Integration of Spiritually Transformative Experiences (https://aciste.org/), IKON (past students; Adelaide and Brisbane campuses), Spiritual Emergence Network Australia, Yoga, 
mindfulness, professional contacts, and online groups (e.g., www. psychforums.com; www.shalomplace.org, forums.psychcentral.com, www.actualized.org/, ozvoices.org, imhu.org/coaching/directory, www.spiritualforums.com/vb/), Facebook groups (e.g., Osho, Spirituality, Mental Health, Positive Psychology, Spiritual Emergence Network, Psychology).

3 Optional extension refers to the practice of continually testing participants past a designated $N$ until the data yields a significant result in the higher $N$. This practice has been critiqued and tested by Bierman et al. (2016).

4 Level of scoring is determined from the sum-of-ranks score and the corresponding $Z$ score. $Z=\left(M-U_{M} \pm 0.5\right) / \sigma_{M}$, "where $M$ is the observed sum-of-ranks, $U_{M}=N(R+1) / 2$, and $\sigma_{M}=N(R-1) / 12$. The 0.5 is the usual continuity correction and has sign opposite to that of $\left(M-U_{M}\right)$ )" (Solfvin, Kelly, \& Burdick, 1978, p. 99). Psi hitting is indicated by a significant sum-of-ranks score that is lower (better) than $\mathrm{MCE}=3.00$.

5 The LOESS ('local regression') line fits a smooth line to so-called 'residuals' (i.e. the difference between the observed values of the dependent variable and the predicted values). Patterns in the scatter of residuals may indicate other relationships not detected in the model.

\section{ACKNOWLEDGMENTS}

Research in this article was made possible by Grant \#16/18 from the Bial Foundation in Portugal. The authors thank the Bial Foundation for their kind support.

\section{REFERENCES}

American Psychiatric Association. (2013). DSM-5: Diagnostic and statistical manual of mental disorders (5 $5^{\text {th }}$ ed.). https://doi.org/10.1176/appi.books.9780890425596

Astin, A. W., Astin, H. S., \& Lindholm, J. A. (2011). Assessing students' spiritual and religious qualities. Journal of College Student Development, 52(1), 39-61. https://spirituality.ucla.edu/researchawards/JCSD-fullfinal ms only.pdf

Beck, A. T., Steer, R. A., \& Brown, G. K. (1996). Manual for the Beck Depression Inventory-II. Psychological Corporation.

Bierman, D. J., Spottiswoode, S. J. P., \& Bijl, A. (2016). Testing for questionable research practices in a meta-analysis: An example from experimental parapsychology. PLOS ONE, 11(5), e0153049. https://doi.org/10.1371/journal.pone.0153049 
Billows, H., \& Storm, L. (2015). Believe it or not: A confirmatory study on predictors of paranormal belief, and a psi test. Australian Journal of Parapsychology, 15(1), 7-35.

Bronn, G., \& Mcllwain, D. (2015). Assessing spiritual crises: Peeling off another layer of a seemingly endless onion. Journal of Humanistic Psychology, 55(3), 346-382. https://doi.org/10.1177/0022167814528045

Buckley, P. F., Miller, B. J., Lehrer, D. S., \& Castle, D. J. (2008). Psychiatric comorbidities and schizophrenia. Schizophrenia Bulletin, 35(2), 383-402. https://doi.org/10.1093/schbul/sbn135

Cooper, E., Rock, A. J., Harris, K. P., \& Clark, G. I. (2015). The factor analytic structure and personality correlates of 'Spiritual Emergency.' Journal of Transpersonal Psychology, 47(2), 242-262. atpweb.org/jtparchive/trps-47-15-02-242.pdf

Goretzki, M., Storm, L., \& Thalbourne, M. A. (2014). Research note: Updating the Spiritual Emergency Scale. Journal of Transpersonal Psychology, 46(2), 240-244.

Goretzki, M., Thalbourne, M. A., \& Storm, L. (2009). The questionnaire measurement of spiritual emergency. Journal of Transpersonal Psychology, 41, 81-97. www.atpweb.org/jtparchive/trps-41-09-01-081.pdf

Goretzki, M., Thalbourne, M. A., \& Storm, L. (2013). Development of a spiritual emergency scale. Journal of Transpersonal Psychology, 45, 105-117. atpweb. org/jtparchive/trps-45-13-02-105.pdf

Grof, C., \& Grof, S. (2017). Spiritual emergency: The understanding and treatment of transpersonal crises. International Journal of Transpersonal Studies, 36(2), 30-43.

Grof, S. (1985). Beyond the brain: Birth, death, and transcendence in psychotherapy. State University of New York Press.

Grof, S., \& Grof, C. (1989). Spiritual emergency: When personal transformation becomes a crisis. Jeremy P. Tarcher.

Grof, S., \& Grof, C. (1991). The stormy search for self: Understanding and living with spiritual emergency. Mandala.

Hales, R. E., Yudofshi, S. C., \& Robert, L. (2014). Textbook of psychiatry. American Psychiatric Publishing.

Harner, M. (1990). The way of the shaman. HarperOne.

Harris, K. P., Rock, A. J., \& Clark, G. I. (2015). Spiritual emergency, psychosis, and personality: A quantitative investigation. Journal of Transpersonal Psychology, $47(2), 263-285$.

Harris, K. P., Rock, A. J., \& Clark, G. I. (2019). Religious or spiritual problem? The clinical relevance of identifying and measuring spiritual emergency. Journal of Transpersonal Psychology, 51(1), 89-118.

Harris, K. P., Rock, A. J., \& Clark, G. I. (submitted). Spiritual emergence(y), psychosis and personality: Investigating the role of schizotypy. International Journal of Transpersonal Studies.

Hood, R. W., Jr. (1975). The construction and preliminary validation of a measure of reported mystical experience. Journal for the Scientific Study of Religion, 14, 29-41.

Hodd, R. W., Jr., Ghorbani, N., Watson, P. J., Ghramaleki, A. F., Bing, M. N., Davision, K., Morris, R. J., \& Williamson, W. P. (2001). Dimensions of the mysticism scale: Confirming the three-factor structure in the United States and Iran. Journal for the Scientific Study of Religion, 40(4), 691-705.

Hood, R. W., Jr., \& Francis, L. J. (2013). Mystical experience: Conceptualizations, 
measurement, and correlates. In K. I. Pargament, J. J. Exline, \& J. W. Jones (Eds.), APA handbooks in psychology, APA handbook of psychology, religion, and spirituality (Vol. 1): Context, theory, and research (pp. 391-405), American Psychological Association. https://doi.org/10.1037/14045-021

Hood, R. W., Morris, R. J., \& Watson, P. J. (1993). Further factor analysis of Hood's Mysticism Scale. Psychological Reports, 73(3, Part 2), 1176-1178. https://doi. org/10.2466/pro.1993.73.3f.1176

Irwin, H. J., \& Watt, C. A. (2007). An introduction to parapsychology (5th ed.). McFarland.

Lange, R., \& Thalbourne, M. A. (2002). Rasch scaling paranormal belief and experience: Structure and semantics of Thalbourne's Australian Sheep-Goat Scale. Psychological Reports, 91(3, Supp.), 1065-1073. https://doi.org/10.2466/ pro.2002.91.3f.1065

Lovibond, S. H., \& Lovibond, P. F. (1995). Manual for the Depression Anxiety Stress Scales (2nd ed.). Psychology Foundation.

Lukoff, D., \& Lu, F. G. (1988). Transpersonal psychology research review topic: Mystical experience. Journal of Transpersonal Psychology, 20(2), 161-184.

May, E. C. (2007). Advances in anomalous cognition analysis: A judge-free and accurate confidence-calling technique. In Proceedings of the 5oth Annual Convention of the Parapsychological Association (pp. 57-63), Halifax, NS, Canada. https://parapsych.org/uploaded_files/pdfs/oo/oo/oo/oo/74/2007_ proceedings.pdf

May, E. C., Faith, L. V., Blackman, M., Bourgeois, B., Kerr, N., \& Woods, L. (2012). A target pool and database for anomalous cognition experiments. Journal of the Society for Psychical Research, 76(2), 94-103.

Palmer, J. (1978). Extrasensory perception: Research findings. In S. Krippner (Ed.), Advances in parapsychological research: Vol. 2: Extrasensory perception (pp. 59-243). Plenum Press.

Palmer, J. (1982). ESP research findings: 1976-1978. In S. Krippner (Ed.), Advances in parapsychological research: Vol. 3 (pp. 41-82). Plenum Press.

Phillips, R. E., III, Lukoff, D., \& Stone, M. K. (2009). Integrating the spirit within psychosis: Alternative conceptualizations of psychotic disorders. Journal of Transpersonal Psychology, 41(1), 61-80.

Schmidt, H. (1970). A PK test with electronic equipment. Journal of Parapsychology 34(3), 175-181.

Schmidt, H. (1973). PK tests with a high-speed random number generator. Journal of Parapsychology, 37(2), 105-118.

Solfvin, G. F., Kelly, E. F., \& Burdick, D. S. (1978). Some new methods of analysis for preferential-ranking data. Journal of the American Society for Psychical Research, 72, 93-109.

Storm, L., Drinkwater, K., \& Jinks, A. L. (2017). A question of belief: An analysis of item content in paranormal belief questionnaires. Journal of Scientific Exploration, 31(2), 187-230.

Storm, L., \& Goretzki, M. (2016). A defense of the Spiritual Emergency Scale: Emergency vs. emergence. Journal of Transpersonal Psychology, 48(2), 190209. atpweb.org/jtparchive/trps-48-16-02-190.pdf

Storm, L., \& Goretzki, M. (2020). Spiritual emergency and psi: Testing the psychic 
opening hypothesis. Journal of Transpersonal Psychology, 52(1), 142-162.

Storm, L., \& Rock, A. J. (2009a). Imagery cultivation vs. noise reduction: Shamaniclike journeying as a psi-conducive alternative to the Ganzfeld protocol. Australian Journal of Parapsychology, 9(1), 5-31. 222.aiprinc.org/documents/ para-aco2_Storm_Rock_2009a (IC).pdf

Storm, L. \& Rock, A. J. (2009b). Shamanic-like journeying and psi: I. Imagery cultivation, paranormal belief, and the picture-identification task. Australian Journal of Parapsychology, 9(2), 165-192. www.aiprinc.org/documents/paraaco2_storm_Rock_2009b (Sh).pdf

Storm, L., \& Thalbourne, M. A. (2005). The effect of a change in pro attitude on paranormal performance: A pilot study using naïve and sophisticated skeptics. Journal of Scientific Exploration, 19(1), 11-29.

Storm, L., \& Tressoldi, P. E. (2017). Gathering in more sheep and goats: A metaanalysis of forced-choice sheep-goat ESP studies, 1994-2015. Journal of the Society for Psychical Research, 81(2), 79-107.

Thalbourne, M. A. (1995). Further studies of the measurement and correlates of belief in the paranormal. Journal of the American Society for Psychical Research, 89, 234-247.

Thalbourne, M. A. (2005). Depression and the sheep-goat variable: Is there a relationship? Journal of the Society for Psychical Research, 69, 143-147.

Thalbourne, M. A., \& Delin, P. S. (1994). A common thread underlying belief in the paranormal, creative personality, mystical experience, and psychopathology. Journal of Parapsychology, 58, 3-38.

Thalbourne, M. A., \& French, C. C. (1995). Paranormal belief, manic-depressiveness, and magical ideation: A replication. Personality and Individual Differences, 18, 291-292.

Thalbourne, M. A., \& Storm, L. (2019). The relationship between paranormal belief and psychopathology with special focus on magical ideation, psychosis, and schizotypy. Australian Journal of Parapsychology, 19, 181-211.

Turner, R. P., Lukoff, D., Barnhouse, R. T., \& Lu, F. G. (1995). A culturally sensitive diagnostic category in the DSM-IV. Journal of Nervous and Mental Disease, 183(7), 435-444. https://doi.org/10.1097/00005053-199507000-00003

Ullman, M. (1977). Psychopathology and psi phenomena. In B. B. Wolman (Ed.), Handbook of parapsychology (pp. 557-574). Van Nostrand Reinhold.

Zebb, B. J., \& Moore, M. C. (2003). Superstitiousness and perceived anxiety control as predictors of psychological distress. Journal of Anxiety Disorders, 17(1), 115-130. http://dx.doi.org/10.1016/So887-6185(02)oo176-7

\section{APPENDIX THE SPIRITUAL EMERGENCY SCALE (SES)}

Introduction: This research is seeking information about extraordinary experiences that occur in the natural, un-intoxicated state, so it is important that you do not include those instances when you may have been under the influence of drugs.

Instructions: Circle one answer only for each item: 'Never', or 'Not Often', or 'Sometimes', or 'Often', or 'Very Often'. [Scoring: 5-point Likert scale, Never = 1, Not Often = 2, Sometimes = 3, Often = 4, Very Often = 5] 


\begin{tabular}{|c|c|c|c|c|c|}
\hline \multirow[t]{2}{*}{1.} & \multicolumn{5}{|c|}{ Have you ever lost your sense of reference as your outer and inner worlds dissolved? } \\
\hline & Never $\bullet$ & Not Often $\bullet$ & Sometimes • & Often $\bullet$ & Very Often $\bullet$ \\
\hline \multirow[t]{2}{*}{2.} & \multicolumn{5}{|c|}{$\begin{array}{l}\text { Have you ever experienced the spontaneous production of complex visual geometrical } \\
\text { images or chants inside your head? }\end{array}$} \\
\hline & Never $\bullet$ & Not Often • & Sometimes $\bullet$ & Often $\bullet$ & Very Often • \\
\hline \multirow[t]{2}{*}{3.} & \multicolumn{5}{|c|}{$\begin{array}{l}\text { Have you ever heard voices, music or the repetition of mantras, without knowing where } \\
\text { they're coming from? }\end{array}$} \\
\hline & Never $\bullet$ & Not Often $\bullet$ & Sometimes • & Often $\bullet$ & Very Often $\bullet$ \\
\hline \multirow[t]{2}{*}{4.} & \multicolumn{5}{|c|}{$\begin{array}{l}\text { Have you ever experienced intense sensations of energy and/or heat streaming along } \\
\text { your spine? }\end{array}$} \\
\hline & Never $\bullet$ & Not Often $\bullet$ & Sometimes • & Often $\bullet$ & Very Often $\bullet$ \\
\hline \multirow[t]{2}{*}{$5 \cdot$} & \multicolumn{5}{|c|}{ Have you ever experienced the spontaneous desire to create rituals? } \\
\hline & Never $\bullet$ & Not Often • & Sometimes $\bullet$ & Often $\bullet$ & Very Often $\bullet$ \\
\hline \multirow[t]{2}{*}{6.} & \multicolumn{5}{|c|}{$\begin{array}{l}\text { Have you ever undertaken a powerful inner experience that involved a journey into } \\
\text { another world? }\end{array}$} \\
\hline & Never $\bullet$ & Not Often • & Sometimes $\bullet$ & Often $\bullet$ & Very Often $\bullet$ \\
\hline \multirow[t]{2}{*}{7.} & \multicolumn{5}{|c|}{$\begin{array}{l}\text { Have you ever had the ability to move into and out of non-ordinary states of } \\
\text { consciousness at will? }\end{array}$} \\
\hline & Never $\bullet$ & Not Often • & Sometimes $\bullet$ & Often $\bullet$ & Very Often $\bullet$ \\
\hline \multirow[t]{2}{*}{8.} & \multicolumn{5}{|c|}{$\begin{array}{l}\text { Have you ever developed a deep change in consciousness during which you lost contact } \\
\text { with everyday reality? }\end{array}$} \\
\hline & Never $\bullet$ & Not Often $\bullet$ & Sometimes $\bullet$ & Often $\bullet$ & Very Often $\bullet$ \\
\hline \multirow[t]{2}{*}{9.} & \multicolumn{5}{|c|}{$\begin{array}{l}\text { Have you ever experienced insights and/or visions, in which you received secret or sacred } \\
\text { teachings and healing powers to take back to the "ordinary" world? }\end{array}$} \\
\hline & Never $\bullet$ & Not Often $\bullet$ & Sometimes $\bullet$ & Often $\bullet$ & Very Often $\bullet$ \\
\hline \multirow[t]{2}{*}{10.} & \multicolumn{5}{|c|}{$\begin{array}{l}\text { Have you ever experienced an increased connection with animals and plants and the } \\
\text { elemental forces of nature? }\end{array}$} \\
\hline & Never $\bullet$ & Not Often • & Sometimes $\bullet$ & Often $\bullet$ & Very Often • \\
\hline \multirow[t]{2}{*}{11.} & \multicolumn{5}{|c|}{$\begin{array}{l}\text { Have you ever had the experience of dealing with something that has a divine nature and } \\
\text { is radically different from your ordinary perception of the everyday world? }\end{array}$} \\
\hline & Never $\bullet$ & Not Often • & Sometimes $\bullet$ & Often $\bullet$ & Very Often $\bullet$ \\
\hline \multirow[t]{2}{*}{12.} & \multicolumn{5}{|c|}{$\begin{array}{l}\text { Have you ever experienced the sense of becoming one with humanity, nature, the } \\
\text { creative energy of the universe and/or God? }\end{array}$} \\
\hline & Never $\bullet$ & Not Often $\bullet$ & Sometimes $\bullet$ & Often $\bullet$ & Very Often $\bullet$ \\
\hline \multirow[t]{2}{*}{13.} & \multicolumn{5}{|c|}{ Have you ever spontaneously attained profound insights into the nature of reality? } \\
\hline & Never $\bullet$ & Not Often $\bullet$ & Sometimes $\bullet$ & Often $\bullet$ & Very Often $\bullet$ \\
\hline \multirow[t]{2}{*}{14.} & \multicolumn{5}{|c|}{$\begin{array}{l}\text { Have you ever felt a sense of overcoming the usual divisions of the body and mind and } \\
\text { reaching a state of complete inner unity and wholeness? }\end{array}$} \\
\hline & Never $\bullet$ & Not Often • & Sometimes $\bullet$ & Often $\bullet$ & Very Often $\bullet$ \\
\hline \multirow[t]{2}{*}{15.} & \multicolumn{5}{|c|}{$\begin{array}{l}\text { Have you ever experienced going beyond your normal understanding of time and space } \\
\text { and entered a timeless realm where these categories no longer apply? }\end{array}$} \\
\hline & Never $\bullet$ & Not Often $\bullet$ & Sometimes $\bullet$ & Often $\bullet$ & Very Often $\bullet$ \\
\hline
\end{tabular}




\begin{tabular}{|c|c|c|c|c|c|}
\hline \multirow[t]{2}{*}{16.} & \multicolumn{5}{|c|}{ Have you ever been aware of the presence of spiritual entities? } \\
\hline & Never $\bullet$ & Not Often $\bullet$ & Sometimes $\bullet$ & Often $\bullet$ & Very Often $\bullet$ \\
\hline \multirow[t]{2}{*}{17.} & \multicolumn{5}{|c|}{$\begin{array}{l}\text { Have you ever spontaneously received accurate information about things in the past, } \\
\text { present or future, by extra-sensory means? }\end{array}$} \\
\hline & Never $\bullet$ & Not Often $\bullet$ & Sometimes • & Often $\bullet$ & Very Often $\bullet$ \\
\hline \multirow[t]{2}{*}{18.} & \multicolumn{5}{|c|}{ Have you ever spontaneously gained a greater understanding of the cosmos? } \\
\hline & Never $\bullet$ & Not Often $\bullet$ & Sometimes $\bullet$ & Often $\bullet$ & Very Often $\bullet$ \\
\hline \multirow[t]{2}{*}{19.} & \multicolumn{5}{|c|}{ Have you ever spontaneously lost your sense of identity? } \\
\hline & Never $\bullet$ & Not Often $\bullet$ & Sometimes $\bullet$ & Often $\bullet$ & Very Often $\bullet$ \\
\hline \multirow[t]{2}{*}{20.} & \multicolumn{5}{|c|}{$\begin{array}{l}\text { Have you ever been able to see auras around people, animals, plants or other living } \\
\text { things? }\end{array}$} \\
\hline & Never $\bullet$ & Not Often $\bullet$ & Sometimes $\bullet$ & Often $\bullet$ & Very Often $\bullet$ \\
\hline \multirow[t]{2}{*}{21.} & \multicolumn{5}{|c|}{ Have you ever experienced a greater awareness of the interconnectedness of all things? } \\
\hline & Never $\bullet$ & Not Often $\bullet$ & Sometimes $\bullet$ & Often $\bullet$ & Very Often $\bullet$ \\
\hline \multirow[t]{2}{*}{22.} & \multicolumn{5}{|c|}{$\begin{array}{l}\text { Have you ever been overwhelmed by powerful emotions and physical sensations, } \\
\text { concerning yourself and others in various circumstances and historical settings? }\end{array}$} \\
\hline & Never $\bullet$ & Not Often $\bullet$ & Sometimes $\bullet$ & Often $\bullet$ & Very Often $\bullet$ \\
\hline \multirow[t]{2}{*}{23.} & \multicolumn{5}{|c|}{$\begin{array}{l}\text { Have you ever experienced living what seemed to be another life, in another time and } \\
\text { place, in great detail? }\end{array}$} \\
\hline & Never $\bullet$ & Not Often $\bullet$ & Sometimes $\bullet$ & Often $\bullet$ & Very Often $\bullet$ \\
\hline \multirow[t]{2}{*}{24 . } & \multicolumn{5}{|c|}{$\begin{array}{l}\text { Have you ever felt like you have personally witnessed detailed sequences of events taking } \\
\text { place in other historical periods and/or cultures that you have had no previous exposure } \\
\text { to? }\end{array}$} \\
\hline & Never $\bullet$ & Not Often $\bullet$ & Sometimes $\bullet$ & Often $\bullet$ & Very Often $\bullet$ \\
\hline \multirow[t]{2}{*}{25 . } & \multicolumn{5}{|c|}{$\begin{array}{l}\text { Have you ever had the need to fight off or try to control the actions of a negative being } \\
\text { or entity? }\end{array}$} \\
\hline & Never $\bullet$ & Not Often $\bullet$ & Sometimes $\bullet$ & Often • & Very Often $\bullet$ \\
\hline \multirow[t]{2}{*}{26.} & \multicolumn{5}{|c|}{$\begin{array}{l}\text { Have you ever experienced rich connections with mythological symbols from ancient } \\
\text { history? }\end{array}$} \\
\hline & Never $\bullet$ & Not Often $\bullet$ & Sometimes $\bullet$ & Often $\bullet$ & Very Often $\bullet$ \\
\hline \multirow[t]{2}{*}{27.} & \multicolumn{5}{|c|}{$\begin{array}{l}\text { Have you ever felt that you were in the centre of huge events that had cosmic relevance } \\
\text { and were important for the future of the world? }\end{array}$} \\
\hline & Never $\bullet$ & Not Often $\bullet$ & Sometimes $\bullet$ & Often $\bullet$ & Very Often $\bullet$ \\
\hline \multirow[t]{2}{*}{28.} & \multicolumn{5}{|c|}{$\begin{array}{l}\text { Have you ever experienced a visionary state taking you back through your own history } \\
\text { and that of mankind to creation? }\end{array}$} \\
\hline & Never $\bullet$ & Not Often $\bullet$ & Sometimes $\bullet$ & Often $\bullet$ & Very Often $\bullet$ \\
\hline \multirow[t]{2}{*}{29.} & \multicolumn{5}{|c|}{$\begin{array}{l}\text { Have you ever been aware of a cosmic battle being played out between the forces of gooc } \\
\text { and evil or light and darkness? }\end{array}$} \\
\hline & Never $\bullet$ & Not Often $\bullet$ & Sometimes & Often $\bullet$ & Very Often $\bullet$ \\
\hline \multirow[t]{2}{*}{30.} & \multicolumn{5}{|c|}{$\begin{array}{l}\text { Have you ever experienced the destruction of an old sense of identity followed by rebirth } \\
\text { and a renewed purpose for living? }\end{array}$} \\
\hline & Never $\bullet$ & Not Often $\bullet$ & Sometimes $\bullet$ & Often $\bullet$ & Very Often $\bullet$ \\
\hline
\end{tabular}

